\title{
High efficient solar cells and modules based on diamond-like carbon film - multicrystalline Si structures
}

\author{
N.I. Klyui, ${ }^{1}$ O.B. Korneta, ${ }^{1}$ V.P. Kostylyov, ${ }^{1}$ V.G. Litovchenko, ${ }^{1}$ A.V. Makarov, ${ }^{1}$ V.N. Dikusha ${ }^{1}$, \\ L.V. Neselevska ${ }^{1}$, V.I. Gorbulik ${ }^{2}$ \\ ${ }^{1}$ Institute of Semiconductor Physics, NAS of Ukraine, 45 prospect Nauky, 03028 Kyiv, Ukraine \\ Phone: +38(044) 265 6202; fax: +38(044) 265 8342; e-mail: klyui@isp.kiev.ua \\ ${ }^{2}$ Special Design Bureau "Ruta", 248 Rus'ka str., 58023 Chernivtsi, Ukraine
}

\begin{abstract}
In the work the results of investigations of developed and produced solar cells (SC) and modules (SM) characteristics are presented. It has been shown that due to application of hydrogen plasma treatment and deposition of diamond-like carbon films high efficient solar cells may be created. New constructions of solar modules having improved exploitation characteristics were proposed. The efficiency of the proposed scientific and design-technology approaches is illustrated by the example of the SC and SMs with the efficiency of $11-14 \%$ and $11-12.5 \%$, correspondingly.
\end{abstract}

Keywords: multicrystalline silicon, diamond-like carbon films, solar cells, modules.

Paper received 19.03.03; accepted for publication 16.06.03.

\section{Introduction}

The threat of conventional energy resources exhaustion causes the urgency for the investigation of alternative ones. It is known that the solar radiation is practically inexhaustible energy source. Among the methods of converting the solar radiation energy into electrical one the photovoltaics (PV) is one of the most promising. As the evidence one can mention the actual rates of increasing solar cells (SC), solar modules (SM) and batteries (SB) production. For example, during the last five years the PV industry growth rate reached up to $15-30 \%$ per year $[1,2]$. In general, the key concept in reducing the cost of energy produced by means of the SCs is the decreasing the price of semiconductor material, which the SCs are based on. At the present, the silicon is the basic material for the SC fabrication. In recent years, instead of the expensive monocrystalline silicon, the so-called multicrystalline silicon is widely used. The latter is significantly cheaper, and has sufficient photoelectric characteristics to be used for production of efficient SCs. Regarding the [2], the part of multi-Si based solar modules in the year 2000 came to $51 \%$ from the total world value of the SMs produced. As an example the part relating to $\mathrm{SM}$ based on the monocrystalline $\mathrm{Si}$ and amorphous $\mathrm{Si}$ amounted to $32 \%$ and $10 \%$ respectively. Production the solar modules based on the multi-Si, already in year 2000 allowed of reducing the energy cost to $\$ 2.1$ per $\mathrm{W}$. The further reducing predicted to 2010 equals to $\$ 1.5$ per $\mathrm{W}$ [2].

Actually, one of the main tasks at the multi-Si based SC fabrication is the method for parameters improvement, particularly by means of different antireflection and passivation coatings deposition [3]. Also the problem of reducing the mass and overall size parameters, preserving the high efficiency of photoconvertion is of great importance.

In the present work the properties of multi-Si based SCs, covered by antireflection and passivation coating of new type, were studied. The diamond-like carbon (DLC) films were applied. The authors showed such coatings to be effective for the SC based on the mono-Si and to be promising for the SC based on multi-Si, earlier in [4, $5,6]$. The efficiency of such SCs is shown on the example of solar module for domestic purposes, designed by the authors. 


\section{Experimental}

SC samples with a $n^{+}-p-p^{+}$structure, produced from boron doped multi-Si $(\rho=0.1 \div 1.7 \mathrm{Ohm} \cdot \mathrm{cm})$ with grain size from several millimeters to several centimeters were studied. Technological process of a SC fabrication includes procedures of diffusion, gettering, anisotropic etching of front side, and screen-printing of contacts. The contacts to isotype $p-n$ junction at rear side were formed as a continious layer as well as a grid-like one. The sizes of the samples were varied from $1 \times 1$ to $10 \times 10 \mathrm{~cm}^{2}$.

Because of crystallographic orientation of grains is different the efficiency of anisotropic etching of a polycrystalline substrate is sufficiently lower then for a single crystalline one. For this reason, we, instead of anisotropic etching, deposited DLC films as antireflection coatings onto front side of the SC samples.

DLC-films were deposited by PE-CVD (plasma enhanced chemical vapor deposition) method using a setup with a capacitance reactor. The gas mixture consisting of $\mathrm{CH}_{4}, \mathrm{~N}_{2}$ and $\mathrm{H}_{2}$, was used, and deposition was carried out at $125 \mathrm{~W}$ discharge power. Time of deposition was chosen in such a way to provide the optimum thickness of antireflection coating and was equal to $3 \mathrm{~min}$. The film thickness was measured by laser ellipsometer LEF-3M and profilometer "Dektak" $(\sim 5 \mathrm{~nm}$ accuracy of thickness determination).

Spectral dependencies of short-circuit current were measured by certified spectral setup based on MDR-3 monochromator in the regime of constant level of illumination. The light beam was modulated $(20 \mathrm{~Hz})$ and measurements were performed in the spectral range from 0.2 to $1.2 \mu \mathrm{m}$. Calibration of spectral characteristics of SC samples to absolute sensitivity was done according to photo-diode "Quant-1", which has been certified in Russian Center of Testing and Certification (ROSTEST-Moscow). Measurements of light current-voltage (I-V) characteristics of SC and determination of photo-energetic parameters were carried out with the setup for photo technical testing FP (UFI) [7, 8] developed at ISP NANU and certified in State Standard of Ukraine.

\section{Results and Discussion}

The efficiency of using the DLC film as antireflection coatings can be estimated from current-voltage characteristics (Fig. 1) measured before (curve 1) and after the coating deposition and from Table 1 where parameters of the SCs are summarized. One can see that this kind of coating provides significant (in 1.22 times) increasing of short circuit current. Reducing the light radiation losses due to reflection from the SC front surface causes such positive effect [6]. Moreover, DLC film demonstrates a good passivation influence on the SC surface. The last fact is confirmed by the increasing of open-circuit voltage (Fig. 1 and Table 1). Such an efficient passivation of surface recombination centers is provided by hydrogen plasma treatment prior to the deposition process and high concentration of hydrogen in the DLC film that terminates dangling bonds and defects in the silicon wafer. It should be noted that the efficiency of SC increases 1.23 times after deposition of DLC film that is substantially higher than the results obtained before [6]. Using the multi-Si based SC of high initial efficiency the value obtained after the DLC film deposition was equal to $13-14 \%$. However, the performance factor in this case increases only in 1.151.18 times due to slight decreasing of current-voltage characteristic fill-factor after deposition of DLC film. This fact is attributed to increasing of short-circuit current and correspondingly influence of the series resistance at the contact grid/silicon interface.

Fig. 2 shows the experimental spectral characteristics of absolute sensitivity of the same sample before (curve 1) and after (curve 2) deposition of antireflection coating. The high sensitivity of initial sample in the whole spectral range is observed. It reaches up to $0.5 \mathrm{~A} / \mathrm{W}$ at $\lambda=$ $=905 \mathrm{~nm}$. High sensitivity in the long-wave range and the position of spectral characteristics maximum is the

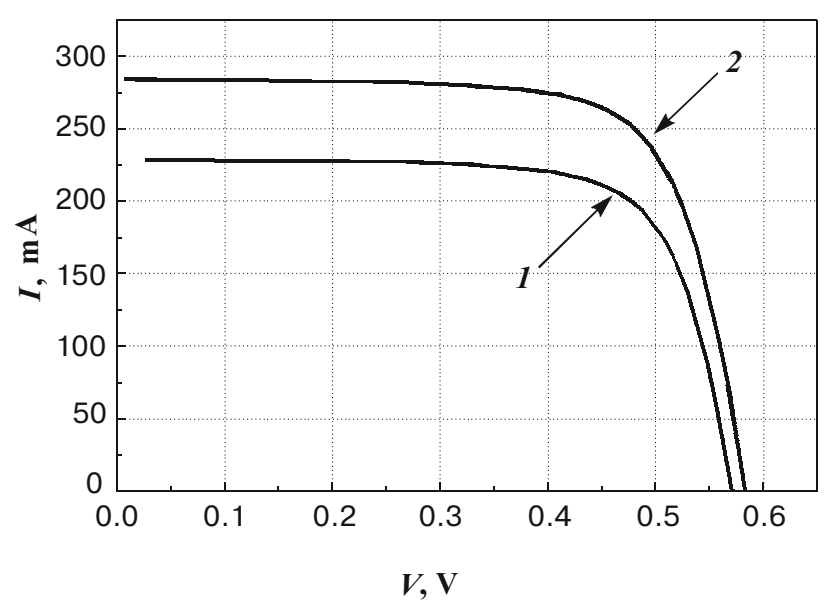

Fig. 1. Current-voltage characteristics of multicrystalline $\mathrm{Si}$ based solar cell; 1 - initial SC; 2 - SC with DLC antireflection coatings.

Table 1. Multi-Si based SCS parameters with and without DLC antireflection coatings.

\begin{tabular}{lllllll}
\hline \hline Sample \# & Spectral conditions & $I_{s c}, \mathrm{~mA}$ & $J_{s c}, \mathrm{~mA} / \mathrm{cm}^{2}$ & $V_{o c}, \mathrm{~V}$ & $F F$ & $\eta, \%$ \\
\hline 1 & AM1.5 & 229 & 22.9 & 0.571 & 0.733 & 9.53 \\
\hline $1^{*}$ & AM1.5 & 285 & 28.5 & 0.583 & 0.728 & 11.7 \\
\hline \hline
\end{tabular}

sample 1 - initial SC; sample1* ${ }^{*}$ SC after the DLC film deposition. 


\section{N.I. Klyui et al.: High efficient solar cells and modules ...}

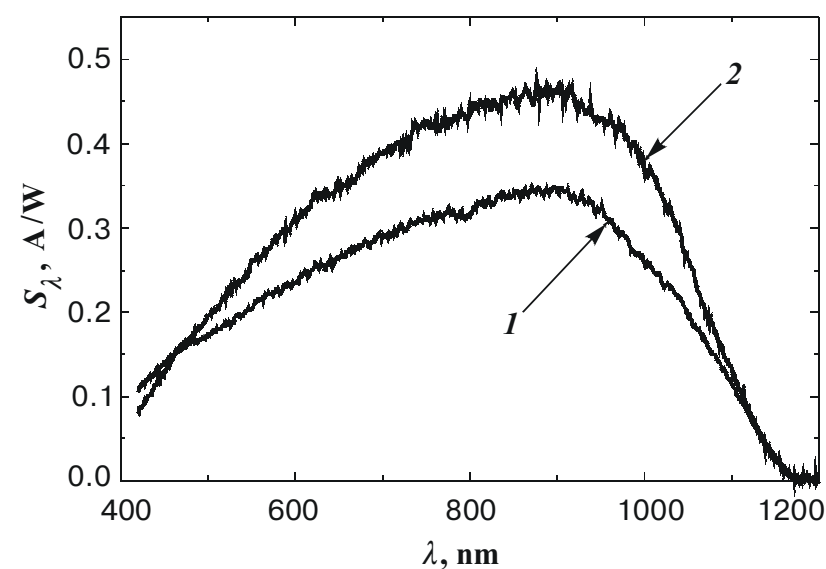

Fig. 2. Experimental characteristics of a spectral sensititvity for multicrystalline $\mathrm{Si}$ based solar cell; 1 - initial SC; 2 - SC with DLC antireflection coating.

evidence of high values of diffusion length for non-equilibrium carriers in the base $p$-region of the $\mathrm{SC}$, that is confirmed by direct measurements $\left(L_{D} \geq 200 \mu \mathrm{m}\right)$, as well as low recombination on the rear surface of $\mathrm{SC}$. The last fact is provided by high quality of isotype junction together with small area of rear contact created in the form of grid. The sensitivity in the short-wave range is also high enough that indicates on the low recombination losses in the high-doped emitter region $\left(n^{+}\right)$and on surface of the SC. Deposition of the DLC film antireflection coating leads to increasing of spectral sensitivity practically in the all range of $\lambda=475-1100 \mathrm{~nm}$, almost not having the influence on very short-wave and long-wave sensitivity of SC $(\lambda<475 \mathrm{~nm}$ and $\lambda>1100 \mathrm{~nm})$. The characteristics are almost identical in that ranges.

The solar modules (Fig. 3) represent a sealed frame structure, which is close in basic characteristics to structure solar module of high power (peak output power more than $50 W_{p}$ ). As a front transparent protective coating the polymethyl methacrylate plastic with the thickness of $2 \mathrm{~mm}$ was used ( 2 in Fig. 3a). The rear protective coating is fiberglass plastic plate with the thickness of $1 \mathrm{~mm}$ ( 9 in Fig. 3a). Interelement connections were made by ultrasonic micro welding using the aluminum foil buses of thickness and width equal to $0.03 \mathrm{~mm}$ and $1.5 \mathrm{~mm}$, correspondingly (4 in Fig. 3a). The sealing is made using the transparent silicone sealant compound (5 in Fig. 3a). All solar cells are connected sequentially. Current-collecting aluminum buses are connected (using ultrasonic welding) to transition board, placed on the rear of solar mod- ule protective coating. The transition board, in turn, has layered metalization consisting of copper layer and boron doped nickel layer. Flexible output cables are soldered to the same area. Output contacts of the solar modules are protected from climatic factors by pressurized cover (11 in Fig. 3a). Characteristics of the modules are presented in Table 2. Schematic view of the modules from the front side is given in Fig. $3 \mathrm{~b}$.

The tests of the SMs at AM1,5 conditions using the simulator of solar radiation on the base of BRILUX B7$500 \mathrm{~W}$ halogen floodlights were carried out. Illumination nonuniformity for the simulator was not more than $7-8 \%$.

Under testing the light current-voltage characteristic $I(V)$ was measured and from the characteristic the following SM parameters were calculated:

- Short-circuit current $I_{s c}$;

- current density of a short circuit $J_{s c}$;

- open-circuit voltage $V_{o c}$;

- fill-factor of current-voltage characteristic $F F$;

- maximum output specific electric power of a solar module, $\mathrm{W} / \mathrm{m}^{2}$;

- value of a photocurrent in a point of maximum output power $I_{m}$;

- density of a photocurrent in a point of maximum output power, $\mathrm{mA} / \mathrm{cm}^{2} I_{m}$;

- value voltage in a point of maximum output power $V_{m}$;

- efficiency $h$.

The light current-voltage characteristics of SM \#1 and \#2 at AM1,5 conditions are shown in Fig. 4, and calculated SM parameters are summarized in Table 3. The obtained data allows us to conclude, that the developed and produced SCs and SMs on the base of multicrystalline silicon demonstrate high enough values of power parameters. So, for example, open-circuit voltage $V_{o c}$ and short-circuit current density $J_{s c}$ for the typical SC reaches $0.56 \mathrm{~V}$ and $\sim 28-30 \mathrm{~mA} / \mathrm{cm}^{2}$, respectively (Table 1 ). As a result, the SMs corresponding characteristics are also high (see Table 3). Besides, FF high value for the module M1 $(F F=0.72)$ testifies to correctly selected the SMs topology and design. It allows us to minimize series resistance and ohmic losses in the module. The efficiency of the developed and produced SMs is high enough and close to $11.15-12.5 \%$ (Table 3 ).

The problem of sealing was solved using transparent silicon-organic sealant. Nowadays this material is used mainly for the assembling the batteries intended for space application. In contrast to conventional methods of "hot" lamination using ethylenevinylacetate $[9,10]$ based sealant films our material provides more reliability of the

Table 2. Characteristics of modules № 1 and № 2.

\begin{tabular}{l|l|ll}
\hline \hline \multirow{2}{*}{ Operation factors } & \multirow{2}{*}{ Dimension } & \multicolumn{2}{|c}{ Values of parameters } \\
\cline { 3 - 4 } & & M1 & M2 \\
\hline Overall dimensions & $\mathrm{mm}$ & $225 \times 353 \times 15$ & 0.18 \\
\hline Weight & $\mathrm{kg}$ & $120 \times 225 \times 15$ \\
\hline SC quantity & pieces & 14 & 8 \\
\hline \hline
\end{tabular}


N.I. Klyui et al.: High efficient solar cells and modules ...
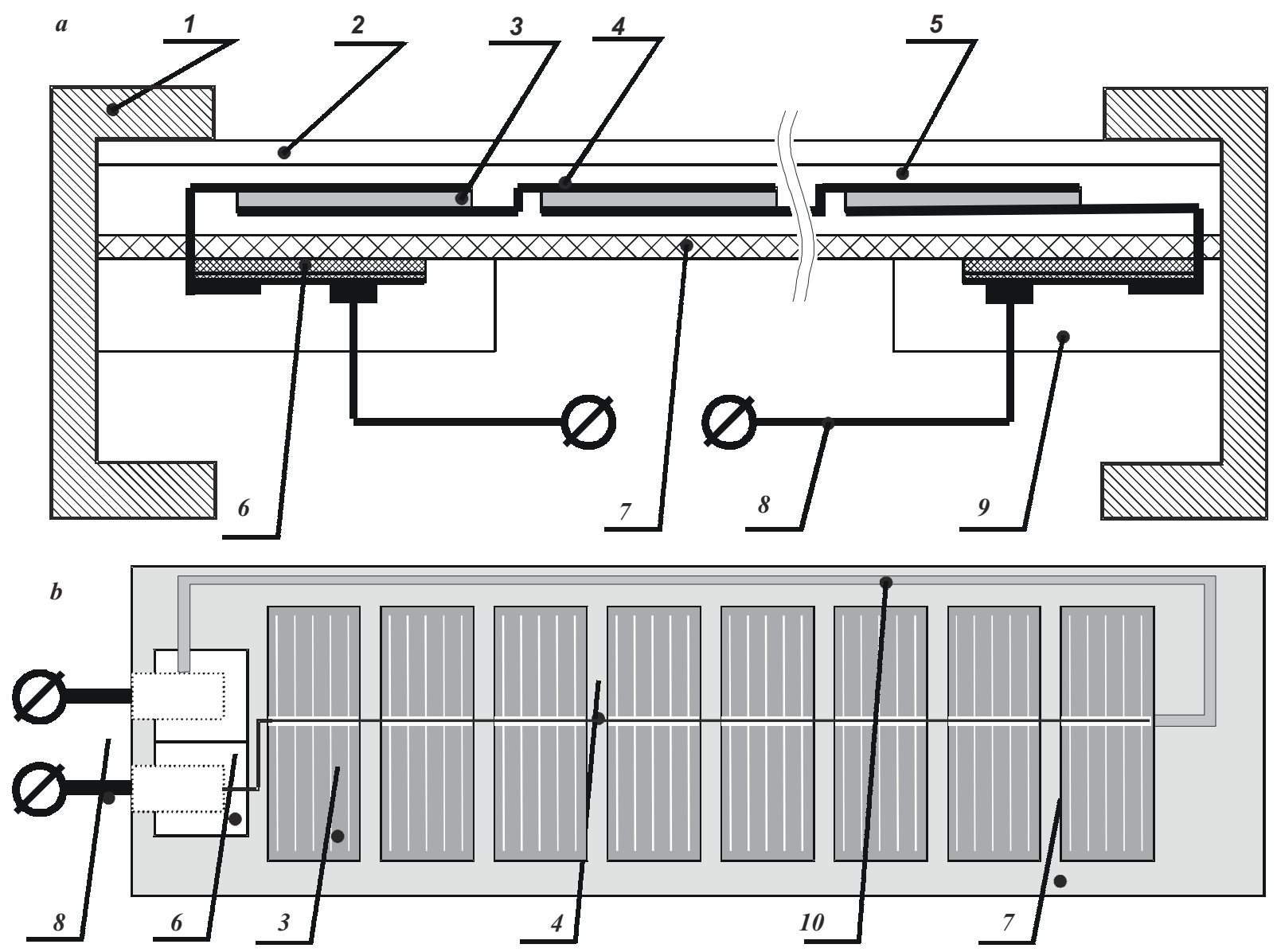

Fig. 3. Structure of experimental solar modules. 1 - Aluminum alloy framework. 2 - Transparent protective coating (polymethyl methacrylate). 3 - Solar cells. 4 - Switching buss (aluminum flat bar $d=0.03 \mathrm{~mm}, b=1.5 \mathrm{~mm}$ ). 5 - Transparent silicon sealant compound. 6 - Transition board (metallized fiber-glass plastic). 7 - Backside protective coating (fiber-glass plastic). 8 - Flexible output cables. 9 - Pressurized cover. 10 - Switching bus (aluminum flat bar $d=0.03 \mathrm{~mm}, b=5 \mathrm{~mm}$ ).

Table 3. Photovoltaic power parameters of solar modules $\left(\mathrm{AM} 1.5, t=28^{\circ} \mathrm{C}\right)$.

\begin{tabular}{l|l|l|l|l|l|l|l|l|l|l|l}
\hline \hline Module & Area, $\mathrm{cm}^{2}$ & $I_{s c}, \mathrm{~A}$ & $J_{s c}, \mathrm{~mA} / \mathrm{cm}^{2}$ & $V_{o c}, \mathrm{~V}$ & $I_{m}, \mathrm{~A}$ & $J_{m}, \mathrm{~mA} / \mathrm{cm}^{2}$ & $V_{m}, \mathrm{~V}$ & $P_{e l}, \mathrm{~W}$ & $P_{\text {fall }}, \mathrm{W}$ & $F F$ & $\eta, \%$ \\
\hline M1 & 140 & 0.28 & 28 & 7.82 & 0.25 & 25 & 6.26 & 1.565 & 12.5 & 0.72 & 12.5 \\
\hline $\mathrm{M} 2$ & 80 & 0.312 & 31.2 & 4.45 & 0.264 & 26.4 & 3.38 & 0.89 & 8 & 0.64 & 11.15 \\
\hline \hline
\end{tabular}
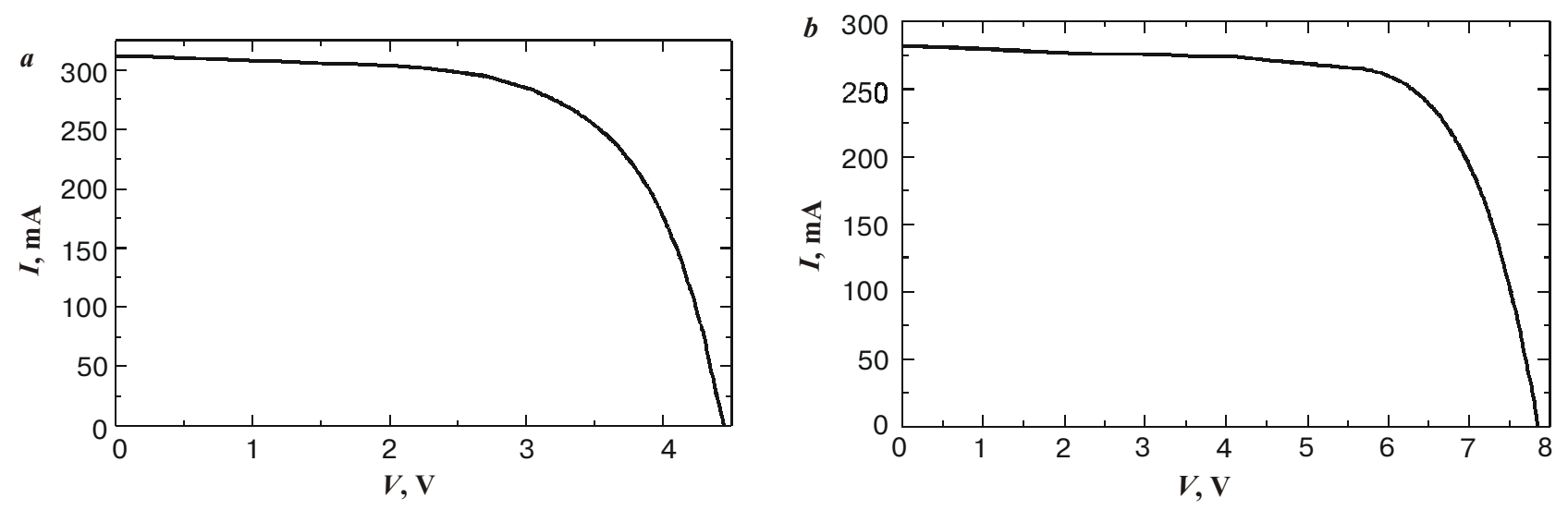

Fig. 4. Light current-voltage characteristic SM \#1(a) and SM \#2 (b) at conditions AM1.5, $t=28{ }^{\circ} \mathrm{C}$. 


\section{N.I. Klyui et al.: High efficient solar cells and modules ...}

module in the open space conditions (ultraviolet radiation, low temperature, sharp temperature drops, vacuum). The investigations performed by the authors showed technical and economic advisability of applying the siliconorganic sealant for terrestrial solar modules production.

General view of typical developed and produced SCs based on diamond-like carbon film -multi-Si structures and modules are presented in Figs 5, 6.

In conclusion, it has been shown that hydrogen plasma treatment and deposition of passivation and antireflection diamond carbon films are very effective procedures in technology of multi-Si based solar cell production. Due to application of the procedures high efficient $(\eta=11-14 \%)$ solar cells have been created. High efficient modules $(\eta=11-12.5 \%)$ for domestic purposes were also fabricated using new design-technology approaches.

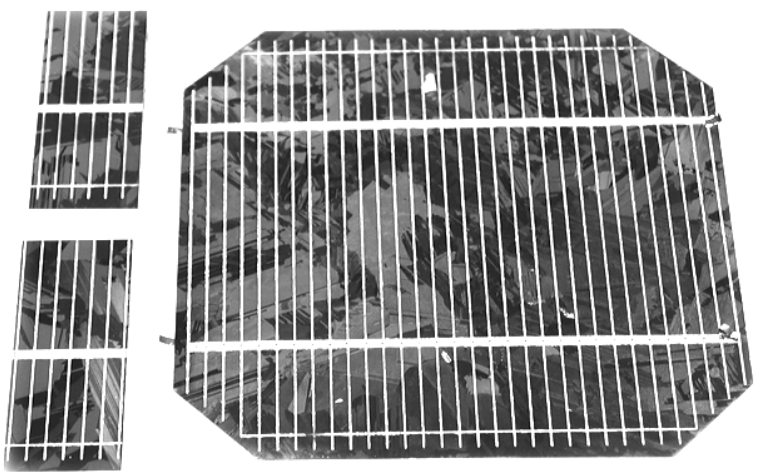

Fig. 5. General view of typical developed and produced solar cells based on diamond-like carbon film - multi-Si structures. $a$-size $2 \times 5 \mathrm{~cm}^{2} ; b-$ size $10 \times 10 \mathrm{~cm}^{2}$.

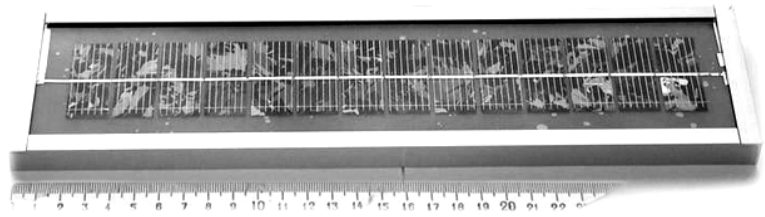

Fig. 6. General view of the typical developed and produced solar module SM \#1.

\section{Acknowledgement}

The work was supported by Science and Technology Center in Ukraine (STCU project U-0-31).

\section{References}

1. T.M. Bruton, General trends about photovoltaics based on crystalline silicon // Solar Energy Materials and Solar Cells. 72, p. 3 (2002)

2. Dominique Sarti, Roland Einhaus, Silicon feedstock for the multi-crystalline photovoltaic industry // Solar Energy Materials and Solar Cells. 72, p. 27 (2002).

3. A.P. Gorban, V.P. Kostylyov, A.V. Sachenko, A.A. Serba, V.V. Chernenko. Development of physical and technical fundamentals for fabrication the solar photoconverters and solar modules for space and terrestrial application // Aviacionnokosmicheskaja tekhnika i tekhnologija. 8, pp. 83-87 (1999).

4. V.G. Litovchenko, N.I. Klyui, Solar Cells Based on DLC Film-Si Structures for Space Aplication // Solar Energy Materials \& Solar Cells. 68,- pp. 55-70 (2001).

5. N.I. Klyui, V.G. Litovchenko, A.G. Rozhin, V.N. Dikusha, M. Kittler, W. Seifert, Silicon solar cells with antireflection diamond-like carbon and silicon carbide films // Solar Energy Materials \& Solar Cells. 72,- pp. 597-603 (2002).

6. N.I. Klyui, V.G. Litovchenko, A.B. Korneta, V.P. Kostylyov, V.I. Gorbulik, U.Kh. Gaziev, M.U. Junklich, V.G. Dyskin, R.A. Muminov, Z.C. Settarova, M.N. Tursunov, Characteristics of poly-Si based solar cells with different antireflection and protective coatings // Heliotekhnika. 4, pp. 3-10 (2002).

7. A.P. Gorban, V.P. Kostylyov, Selected problem of solar energy photoconverters metrology // Proceedings of $5^{\text {th }}$ sci.tech. conference "Metrology provision of temperature and physics measurement". pp. 246-247 (1994).

8. A.P. Gorban, V.P. Kostylyov, A.V. Sachenko, About the enhancement the precision of measurement the photoenergetic parameters of photoconverters using simulators non corrected by the solar spectrum // "Non-conventional sources transmitting systems and energy converters" Collected scientific works. Part 1, pp. 33-34 (1997).

9. Albert K. Plesing, Sabine Degiampietro, Peter Pert, Laminated film material for solar cell encapsulation and their influence in PV-module production and develoment // Proceeding of the 2nd Wold Conference on Photovoltaic Energy Conversion 6-10 July, 1998 (Vienna, Austria) pp.1915-1919.

10. M. Pellegrino, A.Parretta, A.Sarno, A survey on the electrical insulation behavior of the PV module encapsulant materialdeveloment // Proceeding of the 2nd Wold Conference on Photovoltaic Energy Conversion 6-10 July, 1998 (Vienna, Austria) pp. 1926-1929. 